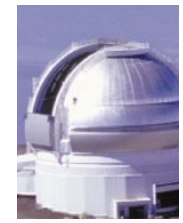

Clear vision

New plans approved for astronomy in Hawaii p872

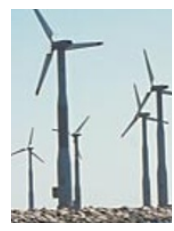
Wind of change? UK government told to spend more on renewable energy p873

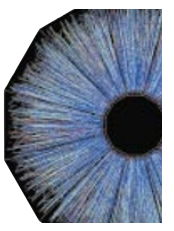
Gold strike US facility opens bid to mimic the start of the Universe p874

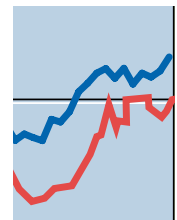

The price is right Imminent genome draft breathes life into biotech shares p875

\title{
German fraud inquiry casts a wider net of suspicion...
}

Alison Abbott, Munich

The fallout from Germany's most notorious case of alleged systematic scientific fraud is proving even more damaging than expected to the reputation of the country's clinical research. Attention had previously focused on a cancer researcher who had worked at the universities of Freiburg, Berlin and Ulm, but it is now suspected that other top clinical professors may have been involved in possible scientific misconduct.

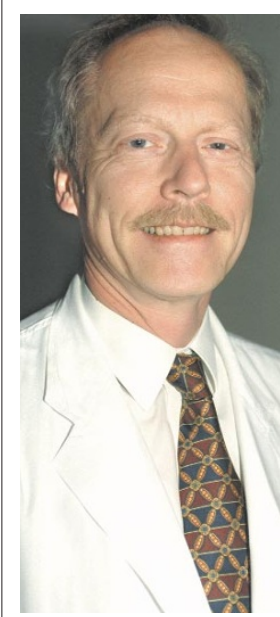

Such suspicions were raised in a report published earlier this week by a task force that has been analysing the publications of Friedhelm Herrmann, who was first accused of fraud in 1997, and who now works as a private practitioner.

The Deutsche Forschungsgemeinschaft (DFG), Germany's research council, has followed up suspiMertelsmann: data in cions raised by the one of his papers are task force and has under investigation. launched a formal investigation into a paper published in the journal Blood in 1994, of which Herrmann was not an author.

The task force, a small team of scientists headed by Ulf Rapp, a cell biologist from the University of Würzburg, has over the past two years been analysing the data in 347 papers published by Herrmann between 1985 and 1996. The researchers used computer programs to look for evidence of copying or manipulation of computer-stored autoradiograms, as well as photographs of suspected proteins and other molecular biological data.

It also interviewed some of the papers' coauthors in a bid to reconstruct the history of each experiment. In its report, published this week, the task force says that 94 papers include data that it thinks have been either definitely or 'highly probably' manipulated.

Fifty-three of these were published jointly

by Herrmann with his former colleague Marion Brach, who has already admitted fabricating data (see Nature 387, 750; 1997). Fifty-nine — including some involving Brach — were co-authored by Roland Mertelsmann, chair of the department of haematology and oncology at the University of Freiburg, in whose department Herrmann had worked.

Mertelsmann, who is well known for being the first scientist to conduct a genetherapy trial in Germany, has accepted responsibility for the suspect publications. But he says that he was only an honorary author, and was therefore unaware of the details of experiments described in them.

Only 132 papers have been given a clean

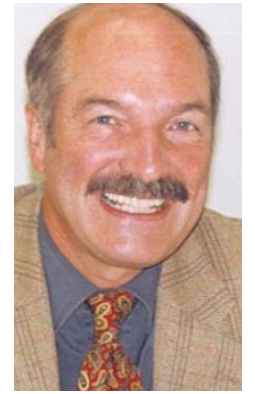

Rapp: has analysed over 300 papers in the past two years.

But, in an effort to gauge the extent of the problem, the task force also looked at five

\section{... as disillusionment reigns in task force}

Participation in the task force investigating allegations of scientific falsification against former cancer researcher Friedhelm Herrmann (see above) seems to have been a generally negative experience for all those involved.

Extensive evidence of data manipulation, a lack of cooperation from some authors, and the lack of interest from many of the journals in which suspicious papers had been published, disillusioned all task-force members.

The task force was set up in 1998 by the DFG, Germany's main university research funding agency (see Nature 395, 533; 1998). Its costs of DM750,000 (US $\$ 370,000$ ) were provided by the DFG and the cancer research charity the Mildred Scheel Foundation.

"At first it was very interesting," says Patrik Grühn, a postdoc on the project. "Data falsification was a new and big thing. But later, after seeing so many falsifications, it got boring, and it makes no difference to the principle involved to prove that 94 papers, rather than 84 , are suspect."

For the leader of the task force, Ulf Rapp of the University of Würzburg, the most frustrating thing was the "moving target" provided by the scientists under investigation. "Everyone pointed their finger at someone else when asked who was responsible for each experiment," he says.

Even given the lack of cooperation from some authors, the extensive 'grey category' of papers, where no strong decision on whether the data quoted might have been tampered with, was also a sign that clinical laboratories require mechanisms for ensuring good scientific record-keeping, he says.

Rapp blames lax standards in clinical research in Germany for the outbreaks of scientific misconduct. He attributes this largely to the fact that clinicians do not have to be formally trained in research methods. This problem is exacerbated by a requirement for clinicians to have a long publication record in order to achieve promotion.

Rapp is also angry that it has so far proved impossible for the courts to bring a legal case against either Herrmann or Marion Brach, and he believes that professional societies have not been sufficiently vociferous in condemning misconduct (see Nature 395, 532-533; 1998).

But in response, Volker Diehl, president of the German Society for Haematology and Oncology, says the society responded rapidly, expelling both Herrmann and Brach, and setting up a group of retired professors to whom young scientists can turn if they are concerned about misconduct in their laboratory. 

randomly selected papers on which Mertelsmann - but not Herrmann — was listed as a co-author. It asked the authors for original patient data to allow them to analyse tables and graphs.

According to Rapp, sufficient original data were provided to fully analyse only one paper, published in Blood in 1994 (volume 84, 1421). This paper investigated a technique to help cancer patients recover from the bone-marrow damage that reduces blood-cell counts following high-dose chemotherapy.

The paper looked at the rate of recovery of blood cells when the patients' own peripheral-blood progenitor cells, taken before chemotherapy, were transplanted back, either unseparated or purified. The paper concluded that recovery was rapid and complete in either case.

But the task force's report says the paper contained many "irregularities and indications that data had been improperly handled". Rapp told Nature that the published graphs describing blood-cell recovery omitted data on a significant proportion of the patients. "If you mis-portray clinical data in important journals you may encourage others to adopt a practice that could put patients at risk," he says.

In response to the task force's findings, the DFG has launched a formal investigation of Mertelsmann and of Lothar Kanz and Wolfram Brugger, respectively professor and senior researcher at the University of Tübingen, and co-authors of the Blood paper.

The University of Freiburg has also opened an internal investigation into the allegations. Kanz declined this week through his lawyers to comment on the investigation; the two other authors did not respond to several requests from Nature to discuss the issues raised by the task force in its report.

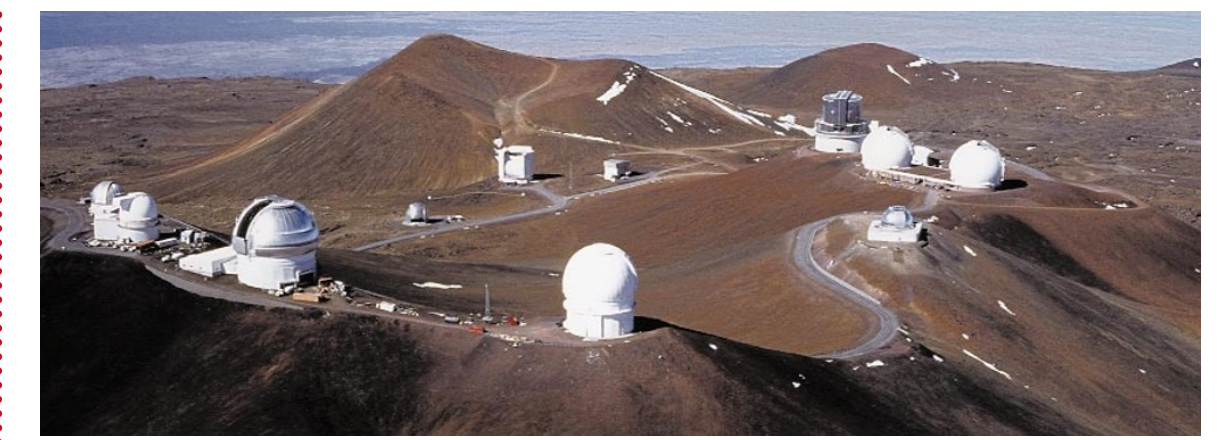

Looking up: expansion plans for the facilities at Mauna Kea have been welcomed by astronomers.

\section{Hawail reaches for the stars with astronomy master plan}

\section{Rex Dalton \& Alison Abbott}

A long-awaited master plan for the future development of astronomy projects on Mauna Kea in Hawaii was approved last week by the University of Hawaii. The agreement comes after two years of negotiations with native Hawaiian cultural groups and environmentalists and a last-minute decision to drop two of the planned facilities.

At the same time, the university has announced that its three-year search for a new director for its Institute of Astronomy is over. Rolf-Peter Kudritzki, currently director of the Institute for Astronomy and Astrophysics at the University of Munich, will take up his new post in October.

Kudritzki says that Mauna Kea has "enormous scientific potential because it is host to so many international observatories".

The master plan to set up an 'astronomy precinct' within the Mauna Kea Science Reserve, and the recruitment of Kudritzki, will allow Hawaii to move forward with a number of plans for expansion and improvements at Mauna Kea. The site is currently home to a number of major facilities, such as the Keck telescope.

Under the plan, three new facilities will be built, five of the existing 13 facilities will be redeveloped, and two of the existing facilities will be expanded.

Native Hawaiians have expressed concern that telescopes and other facilities built near Mauna Kea's 14,000-foot-tall peak would disturb land on which traditional gods are believed to live. Environmentalists have raised concerns about possible damage.

As part of the compromise agreement worked out, the university has cancelled plans for a 4- to 12-metre telescope and an optical/infrared interferometer facility.

In response to local concerns, the master plan calls for an advisory group of native Hawaiians to have a say in future expansion. But native Hawaiians themselves remain sharply divided on Mauna Kea astronomy development. Some leaders have endorsed the master plan, but others continue to threaten legal action to block it.

Kudritzki says the "master plan presents an appropriate balance between the concerns of ecology, religion and astronomy".

\section{Oxford epidemiologist wins apology for promotion slur}

\section{Natasha Loder, London}

Sunetra Gupta, the University of Oxford epidemiologist wrongly accused of having won support for a readership post through a relationship with her head of department (see Nature 403, 353; 2000), has received a retraction and an apology from Roy Anderson, the chair of the appointment committee.

Anderson wrote to Gupta last week unreservedly withdrawing an allegation for which he said there was "no foundation in truth whatsoever and which I accept I never should have made". It has taken Gupta eight months to get the retraction, during which time, she says, she received little support from the university, which she felt had tried to brush the situation under the carpet.

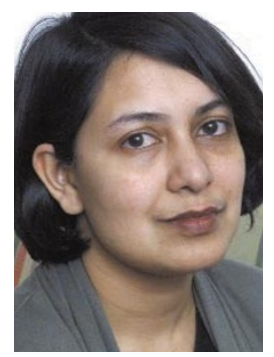

Gupta: waited eight months for apology.
Gupta says that Anderson's comments about her were "totally unacceptable and could not be allowed". She rejects as "highly offensive" criticism from some members of the department of zoology who say she was manipulated into complaining.
The university has already upheld complaints that Anderson had intimidated members of Gupta's appointment committee. His behaviour also led to complaints about his management of the Wellcome Trust Centre for the Epidemiology of Infectious Diseases (see Nature 403, 695; 2000), and ultimately his resignation from the centre, from Oxford University and as governor of the Wellcome Trust.

In his letter to Gupta, Anderson says he was under "a great deal of personal stress at the time". Anderson has also agreed to pay Gupta's legal costs and to make a donation to charity. 